\title{
Chromosome studies in man: past achievements and recent advances
}

\author{
SYLVIA D. LAWLER AND B. R. REEVES \\ From the Department of Cytogenetics and Immunology, Division of Medicine, Institute of Cancer Research \\ and The Royal Marsden Hospital, London
}

\section{Historical survey}

In this section we shall describe the scope of chromosome studies before the introduction of banding techniques.

THE NUMBER OF CHROMOSOMES IN MAN Previous doubt about the number of chromosomes in a human somatic cell was resolved by Tjio and Levan in 1956. Using cells cultured from fetal lungs they demonstrated that the number was 46 . This observation inspired Ford and Hamerton (1956) to examine human meiotic material, and they counted 23 bivalents at first spermatocyte metaphase. During the 10 following years the chromosomal basis of many human abnormalities, both constitutional and acquired, was established.

\section{TECHNIQUES}

The advances in human cytogenetics depended largely on such technical matters as the availability of suitable tissue for chromosomal analysis, the accumulation of an adequate number of dividing cells, and properly dispersed chromosomes.

Much of the work on chromosomal abnormalities in the late fifties was done using fibroblasts cultured from small skin biopsies. This procedure took two or three weeks before sufficient numbers of cells were available for chromosomal analysis. The use of colchicine, a spindle inhibitor, improved yields, arresting and accumulating cells at metaphase. Dispersion of the chromosomes was achieved by hypotonic treatment, and improved spreading was brought about by the use of air-drying methods for the preparation of slides, as opposed to the earlier method which involved squashing the material under a cover slip.

Ford and his collaborators (1958) were the first investigators to use bone marrow for chromosome analysis, and at that time the material was cultured for periods of up to 17 hours.

Received for publication 4 March 1976
A major expansion of chromosome studies was made possible when Hungerford et al (1959) demonstrated that in vitro exposure to phytohaemagglutinin (PHA) could induce some peripheral blood lymphocytes to divide. By this means large numbers of cells in metaphase could be obtained after only two to three days of culture.

In terms of preventive medicine successful in vitro culture of amniotic cells, obtained by the technique of amniocentesis, was an important development. This allowed the prenatal diagnosis of chromosomal abnormalities present in a fetus to be made (Steele and Breg, 1966).

\section{IDENTIFICATION OF CHROMOSOMES}

Structurally, each metaphase chromosome consists of a long and a short arm, divided into two chromatids and united at the centromere. Chromosomes with little material in the short arm are called acrocentric, and these may be satellited-having a small amount of extra material associated with the short arm. Metacentric chromosomes have median centromeres.

At a meeting of the Human Chromosomes Study Group in 1960, guide lines were laid down for the classification of individual chromosomes within the human karyotype. With the staining techniques available in the fifties and sixties, the following chromosomes were individually identifiable according to arm ratio and position of centromere: the $A$ group chromosomes 1,2 , and 3 , and in good preparations the $B$ group numbers 4 and 5 , the $E$ group numbers 16,17 , and 18 , and sometimes the $Y$ chromosome. The chromosomes in groups $\mathrm{C}$ (6-12 and $X), D(13-15), F(19$ and 20), and G (21 and 22) were not readily distinguishable from other members within their groups on morphological grounds.

Further identification of individual chromosomes was achieved by the technique of autoradiography. This involves the use of a radioactive DNA precursor, thymidine, and the subsequent location of sites of DNA synthesis. It was found to be a satisfactory, if time-consuming and expensive, method of distinguishing between the numbers 4 and 5 of the $B$ 
group, usually between 13,14 , and 15 of the $\mathrm{D}$ group, and sometimes numbers 21 and 22 of the $G$ group. Genetic inactivation of one of the two $\mathrm{X}$ chromosomes in the cells of normal females was proposed by Lyon (1961) to provide a mechanism for gene dosage compensation. The genetically inactive X chromosome synthesizes its DNA later in the mitotic cycle than its active homologue, and can thus be identified autoradiographically by its high grain count in cells labelled late in the DNA synthetic phase of the cell cycle.

\section{CONSTITUTIONAL ABNORMALITIES Autosomes}

Lejeune et al (1959) recorded the presence of an extra small acrocentric autosome in patients with Down's syndrome. This was the first description of a chromosomal abnormality in a constitutional disease. At that time the syndrome was already well established as a clinical entity, but the description of other syndromes associated with autosomal trisomies came after the definition of their chromosomal basis.

In the Patau syndrome (Patau et al, 1960) an extra $D$ group chromosome was found to be present and in the Edwards' syndrome an extra E group chromosome was implicated. In the original description the extra chromosome was designated a number 17 (Edwards et al, 1960) but later, on grounds of chromosomal morphology, the syndrome came to be associated with trisomy 18 (Smith et al, 1962). These, the commonest trisomic conditions, can be compatible with survival during intrauterine life and for variable periods thereafter. However, a high frequency of chromosomal abnormalities is found in fetuses which have been spontaneously aborted. The early literature concerning spontaneous abortions was reviewed and the procedures for chromosome studies were standardized at the Geneva Conference (1966). At that time the frequency of chromosome abnormalities in spontaneous abortuses was: $3 \cdot 3 \%$ triploidy, $8.0 \%$ trisomy, $4.1 \% \mathrm{XO}$ or $\mathrm{C}$ group monosomy, and $4 \%$ other abnormalities. Two recent estimates of the contribution of chromosomal abnormalities to fetal wastage are given in table I.

The first observation of a translocation chromosome, as part of a viable human genome, was made by Polani et al (1960), who described a female with Down's syndrome having only 46 chromosomes. This patient was effectively trisomic for a $G$ group chromosome, because in addition to a normal $G$ group complement one member of the $\mathbf{D}$ group had a $G$ group chromosome translocated onto it. Recognition of other translocation chromosomes involving centromeric fusion of two $G$ group chromosomes soon followed (Fraccaro et al, 1960). The $D / G$ translocations were subsequently identified by

\begin{tabular}{|c|c|c|}
\hline $\begin{array}{l}\text { Spontaneous } \\
\text { Abortion }\end{array}$ & $\begin{array}{l}\text { \% with Chromosome } \\
\text { Abnormality }\end{array}$ & Reference \\
\hline $\begin{array}{l}\text { Up to } 12 \text { weeks' } \\
\text { gestation } \\
\text { All gestation times }\end{array}$ & $\begin{array}{l}60 \cdot 4 \\
28 \cdot 2\end{array}$ & $\begin{array}{l}\text { Boué et al (1975) } \\
\text { Alberman et al (1975) }\end{array}$ \\
\hline
\end{tabular}

autoradiography to be between number 14 and 21 in the majority of cases (Hecht et al, 1968).

The first example of deficiency of the genome due. to chromosomal deletion present at birth was des- $\vec{\omega}$ cribed by de Grouchy et al (1963). A mentally retarded child with multiple congenital abnormalities? was found to have a deletion in the short arm of i chromosome 18. Another syndrome, the so-called $v$ 'cri du chat', was found to be associated with air deletion in the short arm of a B group chromosome. 6 Although it was difficult to decide which member of윽 the B group was involved, Lejeune et al (1963) con- cluded that it was a number 5 . This was subsequently $\check{\subseteq}^{-}$ confirmed by autoradiography (German et al, 1964).

\section{Sex chromosomes}

Knowledge of the chromosomal basis of some of the sex chromosome abnormalities preceded the vis-O ualization of the chromosomes. This was due to the discovery of sex chromatin by Barr and Bertram (1949) and their interpretation that the Barr bodies, $\frac{\circ}{\mathbb{Q}}$ seen in interphase nuclei, represent the fused heterochromatic regions of the two $\mathrm{X}$ chromosomes in aO을 normal female cell. Males 'with Klinefelter syndrome (XXY) were found to exhibit sex chromatin and females with Turner's syndrome (XO) were found to lack it. Confirmation of the presence of an extra용 chromosome in the Klinefelter syndrome and aomissing one in Turner's syndrome came in 1959?. (Ford et al, 1959; Jacobs and Keay, 1959; Jacobs ando̊ Strong, 1959; Tjio et al, 1959). The stigmata of 2 Turner's syndrome are also found in patients witho structurally abnormal X chromosomes (Mittwoch, 1967). The technique of autoradiography proved use-o ful in the investigation of such cases; the abnormal $\mathrm{X}$ was generally found to be genetically inactivated? and thus late-labelling.

Patients with the testicular feminization syndrome, who are female in appearance but have undescendedo testes, were found to have an XY chromosome con stitution (Jacobs et al, 1959).

The 47 XYY constitution was first described in $a^{\infty} \rightarrow$ phenotypically normal male (Hauschka et al, 1962). 0 The presence of an extra $Y$ chromosome has beeno found to be associated with heights of over $6 \mathrm{ft}(1.8 \mathrm{D}$ $\mathrm{m})$ in males and implicated as a cause of antisocia市 behaviour because of the high proportion of inmates of security hospitals who were found to have this 
karyotype (Jacobs et al, 1965; Casey et al, 1966). However, in a survey of newborn males the incidence of XYY was found to be $1: 700$ (Ratcliffe et al, 1970), suggesting that some individuals with this karyotype grow up to be law-abiding citizens.

\section{MOSAICISM}

Any of the constitutional chromosomal anomalies may be present in the mosaic form. In this case the individual shows a mixed population of cells, usually one with normal and the other with abnormal karyotypes. The proportion of cells of each type in different tissues may vary, and the degree of mosaicism affects the overall phenotype of the individual. Mosaicism can result from mitotic errors during early cleavage of the zygote but it may occur in somatic tissues at any stage of life. Acquired mosaicism is seen in the bone marrow of elderly males who show a propensity to loss of $Y$ chromosomes in varying proportions of the cells (O'Riordan et al, 1970; Secker Walker, 1971).

\section{INCIDENCE OF CONGENITAL ABNORMALITIES}

In order to relate chromosome aberrations to the spectrum of congenital abnormalities, incidence figures for the commonest ones, both chromosomal and nonchromosomal, are given in table II. It is important to note that neural-tube defects have the highest incidence and that they can be diagnosed antenatally by the raised levels of alpha-fetoprotein in amniotic fluid (Brock and Sutcliffe, 1972). Thus amniocentesis can be used as an aid to diagnosis of both chromosomal and nonchromosomal congenital abnormalities.

\section{ACQUIRED ABNORMALITIES}

\section{Premalignant and malignant disease}

During the sixties the technique of chromosomal analysis began to be applied to tissues from patients with premalignant and malignant disease. It soon became evident that these tissues could retain an apparently normal chromosomal complement, or

\begin{tabular}{lllll}
\hline Chromosomal & & & \multicolumn{2}{l}{ Non-chromosomal } \\
\cline { 1 - 2 } \cline { 5 - 5 } Syndrome & Incidence & & Syndrome & Incidence \\
\hline Down & 1 in 700 & & Spina bifida & 1 in 400 \\
Patau & 1 in 2200 & & Anencephaly & 1 in 500 \\
Edwards & 1 in 4500 & & Cystic fibrosis & 1 in 3800 \\
Klinefelter & 1 in 500 & & & \\
Turner & 1 in 2500 & & \\
\hline
\end{tabular}

Table II Incidence of some congenital abnormalities in live births

Data from Clinical Genetics, 2nd edition, edited by A. Sorsby. Butterworths (1973) might have numerical and/or structural abnormalities of the chromosomes.

The finding of aneuploidy or structural changes in chronic myeloid leukaemia (CML) and refractory anaemias may be cited as examples of premalignant changes. As mentioned earlier, loss of the Y chromosome is a feature of the bone marrow cells of elderly, haematologically normal males, but phenotypically normal males of all ages, having chronic myeloid disorders, may also show Y-chromosome losses from bone marrow cells, a phenomenon which may be attributed to premature ageing (Lawler et al, 1974).

In studies of cervical lesions, chromosome changes were found in both preinvasive and invasive states, but the karyotypic changes were usually more complex in the latter, a general feature of advanced tumours (Atkin and Baker, 1969).

A karyotypic relationship between cells found at different sites can be used to establish metastatic origins. Such a study was performed by Mastrangelo et al (1970), who demonstrated the metastasis of leukaemic cells to the central nervous system in children with acute leukaemia.

Great hopes were raised that human malignancies would be found to be associated with particular chromosomal abnormalities when the Philadelphia chromosome $\left(\mathrm{Ph}^{1}\right)$ and its specific relationship to chronic myeloid leukaemia were discovered by Nowell and Hungerford (1960).

There were some indications of involvement of particular chromosomes in a proportion of cases of other malignant or premalignant diseases, for example the deletion of an F-group chromosome in polycythaemia rubra vera (Kay et al, 1966), abnormalities of chromosomes 17 or 18 in lymphoproliferative disorders (Spiers and Baikie, 1970), and apparently similar structurally abnormal chromosomes in monoclonal gammopathies (Houston et al, 1967). However, the early promise of a high degree of specificity between chromosome abnormalities and disease was not realized. This was partly due to the limitations of the available techniques in defining the chromosomes involved in aneuploidy and structural rearrangements.

\section{Noxious agents}

Acquired abnormalities of the chromosomes can also arise as the result of exposure of the individual to harmful agents such as radiation, viruses or chemicals. Damage to chromosomes can be monitored by studying metaphases in lymphocyte cultures. For example, the amount of radiation to which an individual has been exposed can be estimated by counting unstable abnormalities, dicentrics, rings, and acentric fragments (Buckton and Pike, 1964), 
and comparing the results with standard doseresponse curves obtained from in vitro experiments with known doses of the appropriate radiation.

Since there is some evidence that the use of chemotherapeutic agents may be associated with the development of malignant disease (Hossfeld et al, 1975) monitoring the effects of such drugs on normal tissues is likely to assume greater relevance in clinical medicine (Reeves et al, 1975).

Tough et al (1970) investigated factory workers exposed to benzene in the atmosphere for variable periods of time. In some groups of workers higher than expected numbers of unstable chromosome aberrations were found. The authors concluded, however, that the results had been influenced by the interaction of both age and environment.

The importance of adequate control data in such studies cannot be too strongly emphasized, since chromosome breakage frequencies are known to vary both within and between normal individuals at different times (Littlefield and Goh, 1973).

COMPUTER ANALYSIS

Attempts to program computers to identify human chromosomes, using instructions based on morphological criteria of size and arm ratio, were not altogether successful because of the complexities of the problem. In most laboratories, even those involved in large population screening programmes, the work continued to be done by laboratory personnel. All the laborious work put into the question of computer programming was superseded when Caspersson, Zech et al (1970b) demonstrated that, with a relatively simple staining technique that produced a banding pattern in the chromatin, it was possible for each individual chromosome in the human set to be accurately identified. A new standardized system of nomenclature for the description of banded karyotypes was agreed at a conference held in Paris in 1971.

\section{Banding techniques}

The fundamental biochemical mechanisms underlying the banding patterns observed in metaphase chromosomes have not yet been elucidated, although it seems likely that they reflect local protein-nucleic acid interactions (Evans, 1973; Kurnit, 1974).

\section{Q-BANDING}

This was the first technique to be developed. Treatment of fixed metaphase chromosomes with quinacrine mustard or quinacrine dihydrochloride (Atebrin) results in the appearance of transverse bands of fluorescence along the chromosomes when they are viewed under ultraviolet light (Caspersson,
Zech et al, 1969; Caspersson, Zech et al, 1970b;旁 Caspersson, Lomakka et al, 1971).

The patterns of banding produced are specific for each pair of chromosomes, and do not vary in? different tissues. However, certain chromosome regions possess brightly fluorescing segments which commonly show polymorphisms, in size and staining尺 intensity, between homologous chromosomes and from one person to another. These polymorphicsegments are the centromeric regions of chromosomes. 3 and 4, the short arms and satellites of numbers $13-\vec{\omega}$ 15 and 21-22, and the distal region of the long arm of the Y chromosome in males (Zech, 1969; Pearsono and Bobrow, 1970; Evans et al, 1971).

The main disadvantages of this technique for routine use are the expense of fluorescence microscopyr and the rapidity with which the fluorescence ise quenched, allowing little time for direct analysis of? the cells.

\section{G-BANDING}

The most commonly used methods are undoubtedly $\overrightarrow{0}$ the trypsin-Giemsa technique of Seabright (1971), के which involves brief exposure of the fixed chromosomes to a dilute trypsin solution before staining, and the acetic-saline-Giemsa (ASG) technique of Sumner et al (1971), where staining is preceded by incubationa in a hot salt solution.

The bands obtained are precisely similar to $\mathrm{Q}-\frac{\mathrm{Q}}{\Rightarrow}$ bands, with the following exceptions: the secondaryo constriction regions of chromosomes 1 and 16, which show little or no fluorescence, are very densely stained with Giemsa; while the Y has two small Gbands in the long arm, in contrast to the single large? Q-band. Figure 1 illustrates a male lymphocyteo karyotype stained by a slight modification of the ASG technique.

The various G-banding procedures have the advantage of simplicity, and the staining is per-o manent.

R-BANDING

The banding patterns produced are the reverse of those obtained by G-banding, with the exception of the secondary constriction region of chromosome $9 \mathbb{x}^{N}$ and depend on incubation at higher temperatureso before Giemsa staining (Dutrillaux and Lejeune 1971). A modification of this method uses the fluorescent dye acridine orange in place of Giemsas (Bobrow and Madan, 1973).

\section{C-BANDING}

The so-called $\mathrm{C}$ or constitutive heterochromatin cand be demonstrated by several techniques which demand pretreatment of the fixed chromosomes with an acid and/or alkali before an extended incubationg 


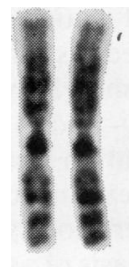

1

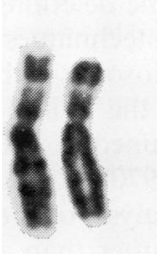

6

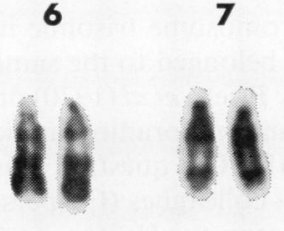

13

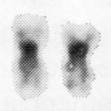

19

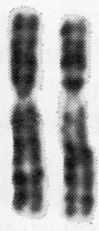

2

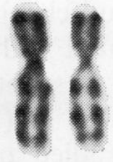

14

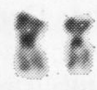

20

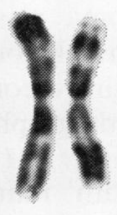

3

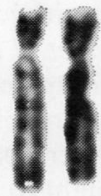

4

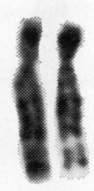

5

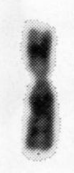

$\mathbf{X}$
Fig 1 G-banded karyotype of a human male.

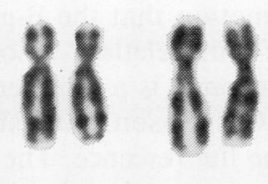

8

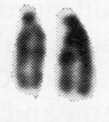

15
9

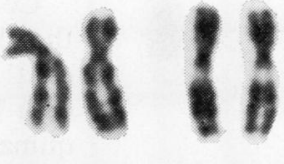

11

10

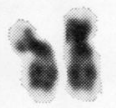

17
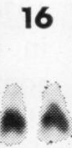

21

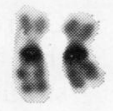

16

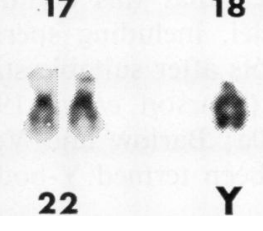

in hot saline (Arrighi and Hsu, 1971; Sumner, 1972; McKenzie and Lubs, 1973). Giemsa-positive regions are found at the centromeres of all the chromosomes, the short arms and satellites of the D- and G-groups, the secondary constriction regions of chromosomes 1,9 , and 16, and the distal long arm of the $Y$. In all these areas, polymorphisms are common and some may be demonstrated in the majority of individuals (Craig-Holmes and Shaw, 1971; Craig-Holmes et al, 1973; McKenzie and Lubs, 1975).

Figure 2 illustrates examples of chromosomes 1, 9, 16 , and Y stained by Q-, G-, and C-banding methods.

\section{ADDITIONAL TECHNIQUES}

In addition to the main banding methods, there are several other techniques available, enabling certain specific areas of the chromosomes to be selectively stained, eg, the satellites of the acrocentrics (Matsui and Sasaki, 1973), the secondary constriction region of chromosome 9 (Bobrow et al, 1972), and the telomeric regions of all the chromosomes (Dutrillaux, 1973).
Two methods, which involve incubation of Sphase cells with the thymidine analogue 5-bromodeoxyuridine (BuDR), enable the late-replicating, heterochromatic X-chromosome in females to be differentiated from its active homologue (Baranovskaya et al, 1972; Latt, 1973). The first authors use Giemsa stain, the heterochromatic X appearing relatively despiralized. In the technique developed by Latt (1973), cells grown in BuDRcontaining medium are given a short pulse of thymidine before fixation. The fixed cells are then stained with the fluorescent dye 33258 Hoechst, the fluorescence of which is quenched by BuDR. The inactive $\mathrm{X}$ exhibits brighter fluorescence than its homologue. If the cells are allowed to incorporate BuDR over two cell cycles, the same staining procedure allows sister-chromatid exchanges (SCE) to be visualized. Perry and Wolff (1974) have added a further step to this method-staining with Giemsa following the fluorescent dye-to give permanent preparations which do not require a fluorescence microscope for their examination. 


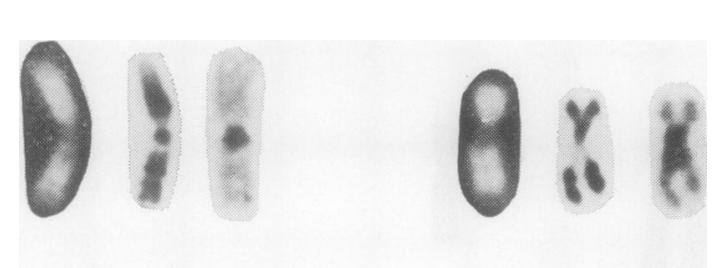

1

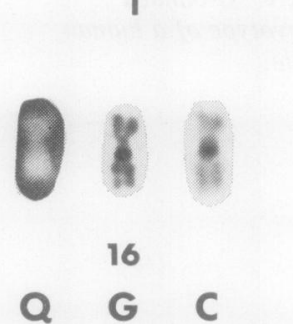

Fig 2 Chromosomes 1, 9, 16, and $Y$ stained by $Q$-, $G$-, and $C$-banding.

\section{INTERPHASE NUCLEI}

Soon after the discovery of the brightly fluorescing $Y$ heterochromatin it was noted that this could be visualized in interphase nuclei, including spermatozoa, as small fluorescent dots after suitable staining with a fluorescent dye (Pearson et al, 1970; Caspersson, Zech et al, 1970a; Barlow and Vosa, 1970). Such structures have been termed Y-bodies, now Y-chromatin.

It was later found that the fluorescent counterparts of the Barr bodies-now called X-chromatincould be similarly demonstrated in a variety of cell types, eg, cultured amnion (Mukherjee et al, 1971), fibroblasts (Wyandt and Hecht, 1971), and hair root cells (Goday et al, 1971).

\section{Application of banding techniques}

In this section we will try to indicate how cytogenetic knowledge has advanced now that many of the limitations of conventional techniques have been overcome.

\section{AUTOSOMAL ABNORMALITIES}

Before the introduction of banding techniques distinguishing between members of the D-group chromosomes depended on autoradiography. The autoradiographic evidence that chromosome 13 was trisomic in Patau's syndrome was confirmed by Miller et al (1971) using Q-banding.

Where D-group chromosomes were deleted difficulties arose in the application of autoradiography for specific identification. The constitutional Dq-
Sylvia D. Lawler and B. R. Reeves $\stackrel{\overbrace{}}{\overline{\bar{\nu}}}$

chromosome found in about a quarter of patients having retinoblastoma was first identified as an interstitial long-arm deletion of chromosome 13 by $\Rightarrow$ Orye et al (1971) using a combination of Q- and Gbanding and autoradiography. This observation was? confirmed by Wilson et al (1973), who re-examined믐. another patient with retinoblastoma, previously? thought to have a 14q- constitution on the basis of an autoradiographic study. In both these cases, the recognition of the interstitial nature of the deletions $\overrightarrow{0}$ was made possible only by use of banding techniques. -

Confirmation that the B-group chromosome with $\vec{\omega}$ the short-arm deletion, associated with the "cri-du= chat' syndrome, is a number 5 was obtained in oneo case by .Caspersson, 'Lindsten et al (1970b) using quinacrine fluorescence. The detailed analysis of the $v$ karyotype favoured a simple deletion rather than a g reciprocal translocation.

The assumption that the chromosome trisomic in음 Down's syndrome and the $\mathrm{Ph}^{1}$ belonged to the same ${ }_{C}^{-}$ G-group pair was challenged by Prieto et al (1970) on the basis of morphological and autoradiographic studies of a single case of CML. The question was $\varphi$ resolved by Caspersson and his colleagues (Caspers- - ) son, Gahrton et al, 1970; Caspersson, Hultén et al, 1970). Although they demonstrated that the trisomy in Down's syndrome involved the smallest auto-⿳亠二口犬 somes, which, according to the Denver criteria, should have been called number 22 , it was decided to $ळ$ designate them 21 so that the established nomencla- $\vec{F}$ ture of trisomy 21 for the syndrome should not be 3 upset. The $\mathrm{Ph}^{1}$ chromosome was therefore assignedas a deleted number 22 (Paris Conference, 1972).

Translocation chromosomes retain the banding patterns characteristic of the chromosomes from? which they are derived. Thus the components of centric fusion can be identified, for example, in patients with Down's syndrome with 46 chromo- $\frac{0}{3}$ somes. The two commonest translocations are between chromosomes 14 and $21 ; 21$ and 21 . This 3 has been confirmed by fluorescent banding (Miller et al, 1971; Uchida and Lin, 1971).

Banding techniques have proved useful in the pre- $N$ cise identification of the supernumerary chromosome in spontaneous abortuses with C-trisomy. Boué et al: (1975) have identified trisomy for chromosome num- $\omega$ bers $7,8,9,10$, and 12 by examining cell lines initiated ${ }^{\circ}$ from spontaneous abortuses. These authors alsoo made some interesting observations concerning times of arrest in uterine development; in abortuses: ${ }^{+}$ with trisomies $13,18,21$, monosomy $X$, and $47 X X Y \underset{T}{0}$ chromosomal complements the time of arrest varies $\frac{\text { ? }}{\mathrm{D}}$ in different cases, the earliest being between five and? six weeks. On the other hand, in fetuses trisomic for

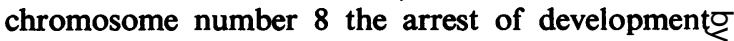
occurs very early, around the fourth week. 


\section{SEX CHROMOSOMES}

X-chromosomes which exhibit structural changes, for example, simple deletions, ring or isochromosome formation, have a late DNA-replication pattern. Such changes have been confirmed by Caspersson, Lindsten et al (1970a) using Q-staining in eight cases of Turner's syndrome.

Translocations involving $\mathrm{X}$-chromosomes and autosomes have been reviewed by Leisti et al (1975). They noted that in the majority of cases where the translocation was balanced, it is the normal $\mathrm{X}$ which is late-labelling. In contrast, they found considerable variation in the replication patterns of the $\mathrm{Xs}$ in cases where the translocation was unbalanced. The inactivation may be entirely random between the normal and abnormal $X$, or involve selectively the normal X only, or particular segments of the translocation chromosome. The authors proposed that the data accumulated so far are consistent with random $\mathrm{X}$-inactivation followed by selection of the most viable cell line.

\section{MEIOTIC STUDIES}

The banding methods have so far been little used in the study of meiotic chromosomes. Pearson and Bobrow (1970) and Caspersson, Hultén et al (1971) have applied the fluorescent technique to a study of chromosomes at diakinesis, and G-banding was used by Luciani et al (1975) to identify pachytene bivalents. The $G_{11}$ technique has been used to observe the meiotic behaviour of the C9 bivalents (Bobrow et al, 1972; Page, 1973), while C-banding has been used by van der Linden et al (1975) in a meiotic study of a male patient with a pericentric inversion of chromosome 4, enabling an assessment of the number of exchanges within the inversion segment to be made.

\section{POLYMORPHISMS}

Among the general population, autosomal polymorphisms appear to be surprisingly common. The Q-banding technique can be used to distinguish between certain homologous regions of chromosome pairs 3 and 4, 13-15, and 21 and 22, by measurements of fluorescent staining intensity. Length variants in the secondary constriction regions of chromosomes 1,9 , and 16 can be demonstrated by C-banding.

In a series of 77 normal newborns, studied with both Q- and C-banding, McKenzie and Lubs (1975) observed 391 variant chromosomes, an average of $5.08 \% 0 \cdot 23 /$ subject. Four of the children had pericentric inversions in number 9 chromosomes; in two cases both homologues were involved. The authors commented that five of the six variant 9s would probably not have been recognized had only conventional staining been used. In another series, studied only with the C-banding technique, Craig-Holmes et al (1973) observed one of 20 adults to have an inverted 9. The frequency of this variant thus seems to be about $5 \%$ in the population so far studied.

Among 50 patients with chromosome abnormalities being investigated for genetic or reproductive defects, Turleau et al (1975) found 11 examples of inversions in chromosome 9 . The high ascertainment in this group of patients may be relevant to their clinical conditions.

Polymorphic variants of chromosomes can be used to determine in which parent and at which meiotic division the non-disjunctional error responsible for a trisomic fetus occurred. Licznerski and Lindsten (1972) carried out family studies in six patients with Down's syndrome. In one family the number 21 chromosomes of the father had small satellites that fluoresced slightly. One of the maternal number 21 chromosomes had an intensely fluorescent satellite region and the other a region showing medium fluorescence. Each of the polymorphic variants was present in the affected child. The deduction could therefore be made that the child had inherited both the maternal number 21 chromosomes, which suggests that the non-disjunction occurred at the first meiotic division in the mother.

A similar technique has been used to define the origin of the extra chromosomal sets in cases of triploid abortuses. Theoretically a triploid conceptus could originate from either parent by abnormalities in first or second meiotic division or by fertilization of the ovum with two sperms. Using polymorphic D-group chromosomes, Jonasson et al (1972b) found evidence in favour of non-reduction at first meiotic division in two mothers and evidence against this in another case.

Polymorphism in the length of the long arm of the $Y$ is well documented (eg Cohen et al, 1966). It has been shown that this variation is largely due to differences in length of the brightly fluorescing portion (Bobrow et al, 1971), which may be entirely lacking in some normal males (Borgaonkar and Hollander, 1971). The $Y$ polymorphism has been shown to have a practical application in a case of paternity, disputed prenatally, that was resolved by Jonasson et al (1972a). They showed similarity in the size of the brightly fluorescent region of the $Y$ chromosome in one of the men involved and the amniotic cells of the fetus. Paternity was confirmed by an autosomal marker and the HLA antigens.

It is desirable to know the origin of particular cells in cases of bone marrow transplantation. Until now the sex chromosomes have proved useful, even when only conventional staining was used to demonstrate that the marrow graft has been successful (Thomas et $a l, 1973)$. The sex chromosomes have also been 
used to determine that malignancy has recurred in the cells of the donor, rather than those of the host, in patients who have a relapse of a leukaemic condition following bone marrow transplantation (Fialkow et al, 1971).

Using Q-staining the $\mathrm{Y}$ chromosome can be identified even in poor quality metaphases, which is useful in the recognition of transplanted cells. It is also possible to apply interphase identification of male cells in this situation.

The use of polymorphisms to distinguish between cells of like sex presents a more difficult problem, being dependent on detailed examination of metaphases of good technical quality. Even under optimal conditions preparations made from bone marrow contain few mitoses that reach the required standard.

\section{TRANSPLACENTAL PASSAGE OF CELLS}

The question of transplacental passage of leucocytes in either direction has been the subject of controversy. The use of fluorescence technique for detection of the $Y$ in interphase has been used to establish that passage of male lymphocytes across the placenta can occur. This technique is satisfactory provided that brilliant fluorescence of one of the maternal autosomes in interphase, mimicking Y-chromatin, can be excluded (Schröder, 1975). The question of whether maternal leucocytes reach the fetal circulation is still controversial. Using quinacrine mustard fluorescence, and mother and son combinations in which the mother had an autosomal fluorescent body not inherited by the child, Schröder (1975) detected four maternal cells in 5853 mitoses in PHA-stimulated cord blood when the child was female and none in 21845 when the child was male.

\section{GENE MAPPING}

The two principal methods are (a) somatic cell hybridization in vitro, and $(b)$ pedigree analysis.

Accurate assignment of genes to particular chromosomes, by either method, generally depends upon an ability to distinguish individual chromosomes with precision.

In hybridization studies, human cells are fused with those of another species, usually mouse or Chinese hamster. In the hybrid cells, human chromosomes tend to be lost preferentially and genes are assigned by inference from concordant segregation of the various markers (usually enzymes) with remaining human chromosome types. More exact mapping, to particular chromosome arms or band regions, depends on the presence of structural rearrangements (deletions or translocations) in the human parental cells. The subject has been recently reviewed by Ruddle (1973).
Chromosome rearrangements and polymorphic $\stackrel{\vec{\sigma}}{.}$ variants are also useful in pedigree analyses and in $\overrightarrow{\vec{F}}$ some instances have confirmed assignments already made on the basis of hybridization techniques. A case in point is the localization of the major histocom- $\frac{\bar{\sigma}}{\bar{\omega}}$. patibility complex (MHC) in man to chromosome $\frac{\rho}{\sigma}$

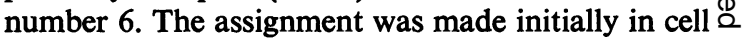
hybrid systems, making use of the known linkage of $\%$ MHC with several enzymes (Chen et al, 1973; $\overrightarrow{0}$ Jongsma et al, 1973) and was later confirmed in a pedigree study of a family in which a pericentric $\vec{\omega}$ inversion of chromosome 6 was segregating (Lamm et al, 1974).

CHROMOSOMAL BREAKAGE

Knowledge of constitutional structural chromosome rearrangements, many of which remained undetected ${ }^{\circ}$ using simple staining methods, has been considerably 을 advanced by the development of chromosome $\vec{c}$ banding. Two population surveys giving data on the exact positions of the breakpoints of structural rearrangements have been published (Jacobs et al, $\vec{\varphi}$ 1974; Turleau et al, 1975), and there is already some. evidence suggestive of non-random breakage. 강 Clarification of this will follow as more information accrues. The establishment of international registries of abnormal karyotypes will doubtless render the retrieval of this kind of information easier.

Several authors have studied the positions of $\underset{\Rightarrow}{\Rightarrow}$ breakpoints found in the chromosomes of cultured 3 lymphocytes exposed to $x$ rays in vitro. These studies showed a higher frequency of breakage involving the pale-staining bands (Caspersson, Haglund $e t$ al, 1972; Holmberg and Jonasson, 1973), and while breaks were generally distributed randomly between the chromosomes, deficits were recorded in: the cases of the X and Y (Seabright, 1973).

A preferential light-band location has also been noted for the breaks induced in vitro by mitomycin-C음 (Morad et al, 1973) and chlorambucil (Reeves and $>$ Margoles, 1974). These studies also demonstrated an over-representation of aberrations involving certain N regions of specific chromosomes, especially the $C-$ band-positive secondary constriction regions of $N$ chromosomes 1,9 , and 16 in the case of mitomycin- $\omega$ $\mathrm{C}$, and only that of number 9 in the case of chlorambucil.

von Koskull and Aula (1973) cultured lymphocytesฐ from five patients with Fanconi's anaemia, a con- $\stackrel{?}{?}$ dition associated with a high rate of chromosome breakage in vitro (Schroeder et al, 1964; German and움 Crippa, 1966) and plotted the positions of the breakpoints in G-banded preparations. They found breakage only in the light-bands, with excesses ino chromosomes $1,2,3,6$, and 13 and deficits in $\mathrm{X}$ and Y. 
An increase in the rate of chromosomal breakage is also a feature of ataxia telangiectasia, in which syndrome chromosomally marked clones may be found in cultures of lymphocytes or fibroblasts. Furthermore there appears to be specific involvement of chromosome 14 in the rearrangements by which the clones are identified (Oxford et al, 1975).

Sister chromatid exchanges have been studied in both ataxia telangiectasia and Bloom's syndrome, a third condition associated with a high frequency of spontaneous chromosome breakage. A 12-fold increase in SCE was found by Chaganti et al (1974) in lymphocytes from patients with Bloom's syndrome, while Galloway and Evans (1975) found no increases over control values in two patients with ataxia telangiectasia.

Studies of cells exposed to certain chemical agents in vitro have shown that increased frequencies of SCE occur with doses which cause only minimal chromosome aberrations (Latt, 1974; Perry and Evans, 1975; Solomon and Bobrow, 1975). If these findings are confirmed in in vivo situations, the SCE test may prove to be a very sensitive method for detecting and monitoring exposure to mutagens/ carcinogens.

SOLID TUMOURS AND LYMPHOMATA

There are few reports in the literature concerned with the application of banding techniques to the study of the chromosomes of solid tumours. This is no doubt due to the difficulty of obtaining an adequate number of suitable dividing cells in such tumours. It would appear that, when this is achieved, it is possible to exploit the banding techniques in order to obtain precise information.

Q-banding studies by Mark et al (1972) and Zankl and Zang (1972) have revealed a constant involvement of chromosome number 22 in meningiomas with benign histology. Most of the tumours were monosomic for chromosome 22 , but occasionally structural changes were found involving loss of material from the long arm. In their study, Mark $e t$ al (1972) analysed 13 tumours and showed that, in addition to the characteristic loss of chromosome 22 , there was a tendency for further selective aneuploidy, gain of number $12 \mathrm{~s}$ with losses of number 1 and 8 chromosomes.

Polyps of the colon have been studied in five patients by Mitelman et al (1974). In several polyps from a patient with hereditary polyposis coli, cells containing extra number 8 and 14 chromosomes were found. Extra number 14 chromosomes were also found in a few cells from two of the four cases in which the polyposis was of the sporadic type. Again there is a suggestion of selective aneuploidy.

Structural changes of chromosome 14 have been associated with both biopsied and cultured material in 10 out of 12 cases of Burkitt's lymphoma (Manolov and Manolova, 1972), and a similar abnormality has also been recorded in one case of plasma cell leukaemia and one of multiple myeloma. In both these latter cases marker chromosomes that could not be defined were also present (Wurster-Hill et al, 1973). These observations suggest a degree of specificity for structural abnormalities of chromosome 14 in malignancies of lymphoid origin.

In the other malignant lymphomata, structural chromosome changes are found almost invariably, numbers $1,3,6,9,12,14$, and 15 being those most frequently involved (Fleischmann et al, 1972; Reeves, 1973; Reeves and Stathopoulos, 1976). Previous suggestions of preferential involvement of chromosomes $17 / 18$ in lymphoid disorders do not appear to have been confirmed by banding techniques.

There are occasional reports of banding studies in tumours of other organs. Falor and Ward (1973) examined six bladder tumours by squashing the preparation and then using a G-banding technique. They described two 'marker' chromosomes which were only partially identified in some of the cells of all six tumours: various other undefined structural changes were observed. A more precisely identified change, the finding of an isochromosome 17 in a single case of metastatic carcinoma of the prostate (Oshimura and Sandberg, 1975), is of interest because of the known association of this anomaly with the blast crisis of CML. Pseudodiploidy in two poorly differentiated breast cancers in elderly women has been demonstrated by Mark (1975). The karyotypes of cells obtained in the ascitic form from two cases of primary ovarian cancer have been shown to exhibit extensive rearrangements by the Q- and G-banding techniques. Some of these would not have been revealed by conventional staining (Tiepolo and Zuffardi, 1973).

\section{MYELOPROLIFERATIVE DISORDERS AND \\ ACUTE LEUKAEMIA}

Until 1973 it was not known whether the material deleted from the number 22 chromosome $\left(\mathrm{Ph}^{1}\right)$ in the myeloid cells of patients with CML was lost from the cell or translocated elsewhere. Rowley (1973) investigated nine patients with CML, using both fluorescence and Giemsa banding techniques, and was able to demonstrate that the material from the number 22 had been translocated on to the distal end of the long arm of a chromosome number $9,9 q+$. This translocation $t(9 ; 22)(q 34 ; q 11)$ is present in the majority of cases but examples of translocation to other sites have been described and are reviewed by Lawler et al (1976).

The heteromorphic fluorescence pattern of the 
satellite region of chromosome number 22 can be used as a marker for the parental origin of each member of the pair. In a case of CML described by Gahrton et al (1973) the $\mathrm{Ph}^{1}$ chromosome was found always to be satellited and the normal number 22 was not. Maternal origin of the satellited chromosome was established, showing that the deleted number 22 was always the same one and therefore supporting the concept of a unicellular origin of the $\mathrm{Ph}^{1}$ anomaly.

Further chromosomal evidence for the clonal origin of CML was contributed by Hayata $e t$ al (1974), who investigated a patient with CML whose number 9 chromosomes could be distinguished from each other by their unusual heteromorphic banding patterns. They found that in every leukaemic metaphase material from the $\mathrm{Ph}^{1}$ was always translocated on to the same number 9 chromosome.

Additonal chromosome changes are frequently associated with the blast transformation of CML; these are the formation of an isochromosome for the long arms of chromosome 17 (Lobb et al, 1972; Lawler et al, 1976) and the acquisition of extra $\mathrm{Ph}^{1}$ chromosomes, generally without duplication of the $9 q+$ (Lawler et al, 1976).

In polycythaemia rubra vera (PRV) the deleted F-group chromosome found in $15-20 \%$ of cases has been shown to be a number $20(20 q-)$ in all cases in which banding has been carried out (Reeves et al, 1972; Rowley, 1974; Shiraishi et al, 1975). There is also a suggestion that another structural change, an interstitial long-arm deletion of chromosome 5, may be associated with a particular form of refractory anaemia (van den Berghe et al, 1974).

Among the other myeloproliferative disorders and acute leukaemias, trisomy for chromosomes 8 or 9 and monosomy of chromosome 7 have been described frequently, while translocations involving chromosomes 8 and 21 and deletions of chromosome 7 have been described in several cases (reviewed in Rowley, 1974; Philip, 1975; Lawler et al, 1975).

The exploitation of the new techniques in cytogenetic studies of acute leukaemia is often hampered by the generally ill-defined nature of the banding patterns observed in leukaemic cells. Nevertheless clones marked by rearranged chromosomes have been found in all types of leukaemia, and some both aneuploid and structural changes may be specific to a minority of cases.

ROLE OF CHROMOSOMES IN NEOPLASIA

For many years this has been the subject of conjecture and debate. From studies of experimental tumours it is known that malignant transformation may take place in the absence of visible chromosome changes, although these generally occur as the

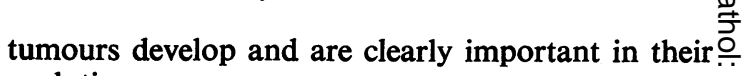
evolution.

In man, we generally cannot relate chromosome $\stackrel{\vec{F}}{+}$ changes, detected at the time malignancy is clinically? apparent, to a time scale of tumour evolution. Use of $\frac{\overline{\bar{D}}}{\overline{\mathrm{n}}}$ the new techniques in prospective studies of patients $\frac{\bar{\rho}}{\bar{\phi}}$ having premalignant changes, and patients with con- $\mathbb{\complement}$ stitutional chromosomal abnormalities that predispose to cancer, offers an approach to the detection of $\overrightarrow{0}$ early changes associated with malignancy. The expansion of our knowledge of the human genetic $\vec{\omega}$ map which can be expected over the next few years? opens up the prospect of defining the role of particu-o lar loci in the malignant process.

\section{Prospects}

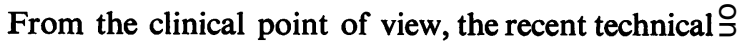
advances offer refinements in diagnosis. This is par- ticularly important in genetic counselling and the investigation of fetal wastage (Kim et al, 1975). We envisage that the use of cytogenetic techniques will $\overrightarrow{0}$ expand, particularly in the fields of monitoring. patients being treated with mutagenic drugs, and the investigation of occupational and environmental hazards.

Extensive population studies will depend on the development of automation. There is no reason why metaphases should not be located automatically but $\stackrel{2}{\Rightarrow}$ the use of computers for karyotype analysis is limited at present by the variability of the biological material. For some time ahead the human eye willo still be essential for analysis.

\section{Glossary}

Acentric fragment

Aneuploidy

Autosome

Bivalents

Chromatin

Constitutive

heterochromatin

Deletion

Deletion, interstitial

Dicentric

Diploidy
Chromosome material lacking centromere that is not an exact multiple of the haploid number: 23

In man, any chromosome other than the sex chromosomes

In meiosis, paired homologous $N$ chromosomes

The substance of the chromosome In man, the centromeric region, $\omega$ secondary constrictions of numbers $O$ 1,9 , and 16 and the long arm of the $Y$, which are characteristically stained by certain techniques and which are $\mathbb{D}$ generally enriched in highly repeated? DNA sequences

Loss of a chromosome segment

Loss of chromosome material, not $\frac{O}{\mathbb{P}}$ involving the ends of a chromosome A chromosome having two centro- $\mathbb{D}$ meres, formed by breakage and $\frac{}{\sigma}$ reunion involving two chromosomes In man, the presence of 46 chromo-? somes
In man, a chromosome complement $O$ 
Genome

Isochromosome

Karyotype

Monosomy

Pericentric inversion

Polymorphism

Pseudodiploidy

Ring

Secondary

constriction

Sex chromosomes

Sister chromatid

exchange

Telomere

Translocation

Triploidy

Trisomy

We should like to thank Dr H. E. M. Kay and Dr Lorna Secker Walker for their constructive criticisms of the manuscript.

\section{References}

Alberman, E., Elliott, M., Creasy, M., and Dhadial, R. (1975). Previous reproductive history in mothers presenting with spontaneous abortions. Brit. J. Obstet. Gynaec., 82, 366-373.

Arrighi, F. E. and Hsu, T. C. (1971). Localization of heterochromatin in human chromosomes. Cytogenetics, 10, 8186.

Atkin, N. B. and Baker, M. C. (1969). Possible differences between the karyotypes of preinvasive lesions and malignant tumours. Brit. J. Cancer, 23, 329-336.

Baranovskaya, L. T., Zakharov, A. F., Dutrillaux, B., Carpentier, S., Prieur, M., and Lejeune, J. (1972). Différenciation des chromosomes $\mathrm{X}$ par les méthodes de déspiralisation au 5-bromodeoxyuridine (BUDR) et de dénaturation thermique ménagée. Ann. Génét., 15, 271274.
Barlow, P. and Vosa, C. G. (1970). The Y chromosome in human spermatozoa. Nature (Lond.), 226, 961-962.

Barr, M. L. and Bertram, E. G. (1949). A morphological distinction between neurones of the male and female, and the behaviour of the nucleolar satellite during accelerated nucleoprotein synthesis. Nature (Lond.), 163, 676-677.

van den Berghe, H., Cassiman, J. J., David, G., Fryns, J. P., Michaux, J. L., and Sokal, G. (1974). Distinct haematological disorder with deletion of long arm of No. 5 chromosome. Nature (Lond.), 251, 437-438.

Bobrow, M. and Madan, K. (1973). The effects of various banding procedures on human chromosomes studied with acridine orange. Cytogenet. Cell Genet., 12, 145-156.

Bobrow, M., Madan, K., and Pearson, P. L. (1972). Staining of some specific regions of human chromosomes, particularly the secondary constriction of number 9. Nat.dre New Biol., 238, 122-124.

Bobrow, M., Pearson, P. L., Pike, M. C., and El-Alfi, O. S. (1971). Length variation in the quinacrine-binding segment of human Y chromosomes of different sizes. Cytogenetics, 10, 190-198.

Borgaonkar, D. S. and Hollander, D. H. (1971). Quinacrine fluorescence of the human Y chromosome. Nature (Lond.), 230, 52.

Boué, J., Boué, A., Deluchat, C., Perraudin, N., and Yvert, F. (1975). Identification of $\mathrm{C}$ trisomies in human abortuses. J. med. Genet., 12, 265-268.

Brock, D. J. H. and Sutcliffe, R. G. (1972). Alpha-fetoprotein in the antenatal diagnosis of anencephaly and spina bifida. Lancet, 2, 197-199.

Buckton, K. E. and Pike, M. C. (1964). Time in culture. An important variable in studying in vivo radiation-induced chromosome damage in man. Int. J. Radiat. Biol., 8, 439 452.

Casey, M. D., Segal, L. J., Street, D. R. K., and Blank, C. E. (1966). Sex chromosome abnormalities in two state hospitals for patients requiring special security. Nature (Lond.), 209, 641-642.

Caspersson, T., Gahrton, G., Lindsten, J., and Zech, L. (1970). Identification of the Philadelphia chromosome as a number 22 by quinacrine mustard fluorescence analysis. Exp. Cell Res., 63, 238-240.

Caspersson, T., Haglund, U., Lindell, B., and Zech, L. (1972). Radiation-induced non-random chromosome breakage. Exp. Cell. Res., 75, 541-543.

Caspersson, T., Hultén, M., Lindsten, J., and Zech, L. (1970). Distinction between extra G-like chromosomes by quinacrine mustard fluorescence analysis. Exp. Cell Res., 63, 240-243.

Caspersson, T., Hultén, M., Lindsten, J., and Zech, L. (1971). Identification of chromosome bivalents in human male meiosis by quinacrine fluorescence analysis. Hereditas (Lund), 67, 147-149.

Caspersson, T., Lindsten, J., and Zech, L. (1970a). The nature of structural $X$ chromosome aberrations in Turner's syndrome as revealed by quinacrine mustard fluorescence analysis. Hereditas (Lund), 66, 287-292.

Caspersson, T., Lindsten, J., and Zech, L. (1970b). Identification of the abnormal B group chromosome in the "cri-duchat' syndrome by QM fluorescence. Exp. Cell Res., 61, 475-476.

Caspersson, T., Lomakka, G., and Zech, L. (1971). The 24 fluorescence patterns of the human metaphase chromosomes-distinguishing characters and variability. Hereditas (Lund.), 67, 89-102.

Caspersson, T., Zech, L., Johansson, C., Lindsten, J., and Hultén, M. (1970a). Fluorescent staining of heteropycnotic chromosome regions in human interphase nuclei. Exp. Cell Res., 61, 472-474.

Caspersson, T., Zech, L., Johansson, C., and Modest, E. J. 
(1970b). Identification of human chromosomes by DNAbinding fluorescent agents. Chromosoma, 30, 215-227.

Caspersson, T., Zech, L., Modest, E. J., Foley, G. E., Wagh, U., and Simonsson, E. (1969). Chemical differentiation with fluorescent alkylating agents in Vicia faba metaphase chromosomes. Exp. Cell Res., 58, 128-140.

Chaganti, R. S. K., Schonberg, S., and German, J. (1974). A manifold increase in sister chromatid exchanges in Bloom's syndrome lymphocytes. Proc. nat. Acad. Sci. (Wash.), 71, 4508-4512.

Chen, T. R., McMorris, F. A., Creagan, R., Ricciuti, F., Tischfield, J., and Ruddle, F. (1973). Assignment of the genes for malate oxidoreductase decarboxylating to chromosome 6 and peptidase $\mathrm{B}$ and lactate dehydrogenase B to chromosome 12 in man. Amer.J.hum. Genet., 25, 200207.

Cohen, M. M., Shaw, M. W., and MacCluer, J. W. (1966). Racial differences in the length of the human $Y$ chromosome. Cytogenetics, 5, 34-52.

Craig-Holmes, A. P., Moore, F. B., and Shaw, M. W. (1973) Polymorphism of human C-band heterochromatin. I. Frequency of variants. Amer. J. hum. Genet., 25, 181-192.

Craig-Holmes, A. P. and Shaw, M. W. (1971). Polymorphism of human constitutive heterochromatin. Science, 174, 702704.

Dutrillaux, B. (1973). Nouveau système de marquage chromosomique: les bandes T. Chromosoma, 41, 395-402.

Dutrillaux, B. and Lejeune, J. (1971). Sur une nouvelle technique d'analyse du caryotype humain. C. R. Acad. Sci. (Paris) [D], 272, 2638-2640.

Edwards, J. H., Harnden, D. G., Cameron, A. H., Crosse, V. M., and Wolff, O. H. (1960). A new trisomic syndrome. (Letter.) Lancet, 1, 787.

Evans, H. J. (1973). Molecular architecture of human chromosomes. Brit. med. Bull., 29, 196-202.

Evans, H. J., Buckton, K. E., and Sumner, A. T. (1971). Cytological mapping of human chromosomes: results obtained with quinacrine fluorescence and the aceticsaline-Giemsa techniques. Chromosoma, 35, 310-325.

Falor, W. H. and Ward, R. M. (1973). DNA banding patterns in carcinoma of the bladder. J. Amer. med. Ass., 226, 1322-1327.

Fialkow, P. J., Thomas, E. D., Bryant, J. I., and Neiman, P. E. (1971). Leukaemic transformation of engrafted human marrow cells in vivo. Lancet, 1, 251-255.

Fleischmann, T., Hakansson, C. H., Levan, A., and Moller, T. (1972). Multiple chromosome aberrations in a lymphosarcomatous tumour. Hereditas (Lund), 70, 243-258.

Ford, C. E. and Hamerton, J. L. (1956). The chromosomes of man. Nature (Lond.), 178, 1020-1023.

Ford, C. E., Jacobs, P. A., and Lajtha, L. G. (1958). Human somatic chromosomes. Nature (Lond.), 181, 1565-1568.

Ford, C. E., Polani, P. E., Briggs, J. H., and Bishop, P. M. F. (1959). A presumptive human XXY/XX mosaic. Nature (Lond.), 183, 1030-1032.

Fraccaro, M., Kaijser, K., and Lindsten, J. (1960). Chromosomal abnormalities in father and mongol child. Lancet, 1, 724-727.

Gahrton, G., Lindsten, J., and Zech, L. (1973). Origin of the Philadelphia chromosome. Tracing of chromosome 22 to parents of patients with chronic myelocytic leukemia. Exp. Cell Res., 79, 246-247.

Galloway, S. M. and Evans, H. J. (1975). Sister chromatid exchange in human chromosomes from normal individuals and patients with ataxia telangiectasis. Cytogenet. Cell Genet., 15, 17-29.

Geneva Conference. (1966). Standardisation of procedures for chromosome studies in abortion. Cytogenetics, 5, 361393.

German, J. and Crippa, L. P. (1966). Chromosomal breakage in diploid cell lines from Bloom's syndrome and Fanconi's anaemia. Ann. Génét., 9, 143-154.

German, J., Lejeune, J., Macintyre, M. N., and de Grouchy, J. (1964). Chromosomal autoradiography in the cri du chat syndrome. Cytogenetics, 3, 347-352.

Goday, C., Egozcueuy, J., and Bafall, E. (1971). Sexchromatin fluorescence in hair-root cells. (Letter.) Lancet, $2,220$.

de Grouchy, J., Lamy, M., Thieffry, S., Arthuis, M., and Salmon, C. (1963). Dysmorphie complexe avec oligophré- $\triangle$ nie: délétion des bras courts d'une chromosome 17-18.C. \) R. Acad. Sci. (Paris), 256, 1028-1029.

Hauschka, T. S., Hasson, J. E., Goldstein, M. N., Koepf, G. $\overrightarrow{0}$ F., and Sandberg, A. A. (1962). An XYY man with progeny indicating familial tendency to non-disjunction. Amer. J. hum. Genet., 14, 22-29.

Hayata, I., Kakati, S., and Sandberg, A. A. (1974). On the monoclonal origin of chronic myelocytic leukemia. Proc. Jap. Acad., 50, 381-385.

Hecht, F., Case, M. P., Lovrien, E. W., Higgins, J. V., V Thuline, H. C., and Melnyk, J. (1968). Nonrandomness of iv translocations in man: preferential entry of chromosomes into 13-15/21 translocations. Science, 161, 371-372.

Holmberg, M. and Jonasson, J. (1973). Preferential location of X-ray induced chromosome breakage in the R-bands of human chromosomes. Hereditas (Lund), 74, 57-67.

Hossfeld, D. K., Holland, J. F., Cooper, R. G., and Ellison, R. R. (1975). Chromosome studies in acute leukemias $\overrightarrow{0}$ developing in patients with multiple myeloma. Cancer Res., 35, 2808-2813.

Houston, E. W., Ritzmann, S. E., and Levin, W. C. (1967). Chromosomal aberrations common to three types of monoclonal gammapathies. Blood, 29, 214-232.

Human Chromosomes Study Group. (1960). A proposed standard of nomenclature of human mitotic chromosomes. Cerebral Palsy Bulletin, 2 (3), Suppl., 1960.

Hungerford, D. A., Donnelly, A. J., Nowell, P. C., and Beck, S. (1959). The chromosome constitution of a human $\overline{\vec{z}}$ phenotypic intersex. Amer. J. hum. Genet., 11, 215-236.

Jacobs, P. A., Baikie, A. G., Court Brown, W. M., Forrest, H., Roy, J. R., Stewart, J. S. S., and Lennox, B. (1959). Chromosomal sex in the syndrome of testicular feminisation. Lancet, 2, 591-592.

Jacobs, P. A., Brunton, M., Melville, M. M., Brittain, R. P.,? and McClemont, W. F. (1965). Aggressive behaviour, $\bar{O}$ mental subnormality and the XYY male. Nature (Lond.), 208, 1351-1352.

Jacobs, P. A., Buckton, K. E., Cunningham, C., and Newton, M. (1974). An analysis of the break points of structural rearrangements in man. J. med. Genet., 11, 50-64.

Jacobs, P. A. and Keay, A. J. (1959). Somatic chromosomes in a child with Bonnevie-Ullrich syndrome. (Letter.) Lancet, 2, 732.

Jacobs, P. A. and Strong, J. A. (1959). A case of human inter- N sexuality having a possible XXY sex-determining mecha-nism. Nature (Lond.), 183, 302-303.

Jonasson, J., Lindsten, J., Lundborg, R., Kissmeyer-Nielson, N F., Lamm, L. U., Petersen, G. B., and Therkelsen, A. J. $\omega$ (1972a). HL-A antigens and heteromorphic fluorescence characters of chromosomes in prenatal paternity investiga-o tion. Nature (Lond.), 236, 312-313.

Jonasson, J., Therkelsen, A. J., Lauritsen, J. G., and Lindsten, J. (1972b). Origin of triploidy in human abortuses. Hereditas (Lund), 71, 168-171.

Jongsma, A., van Someren, H., Westerveld, A., Hagemeijer, $\underset{P}{\oplus}$ A., and Pearson, P. (1973). Localization of genes on human $\mathbb{D}$ chromosomes by studies of human-chinese hamster $\frac{\mathbb{D}}{\mathbb{D}}$ somatic cell hybrids. Assignment of $\mathrm{PGM}_{3}$ to chromosome $\Omega$ C6 and regional mapping of the PGD, $\mathrm{PGM}_{1}$, and PEP-CO genes on chromosome Al. Humangenetik, 20, 195-202. 
Kay, H. E. M., Lawler, S. D., and Millard, R. E. (1966). The chromosomes in polycythaemia vera. Brit. J. Haemat., 12, 507-527.

Kim, H. J., Hsu, L. Y. F., Paciuc, S., Cristian, S., Quintana, A., and Hirschhorn, K. (1975). Cytogenetics of fetal wastage. New Engl. J. Med., 293, 844-847.

von Koskull, H. and Aula, P. (1973). Non random distribution of chromosome breaks in Fanconi's anaemia. Cytogenet. Cell Genet., 12, 423-434.

Kurnit, D. M. (1974). DNA helical structure during C-banding procedure. Cytogenet. Cell Genet., 13, 313-329.

Lamm, L. U., Friedrich, U., Petersen, G. B., Jørgensen, J., Nielsen, J., Therkelsen, A. J., and Kissmeyer-Nielsen, F. (1974). Assignment of the major histocompatibility complex to chromosome No. 6 in a family with a pericentric inversion. Hum. Hered., 24, 273-284.

Latt, S. A. (1973). Microfluorometric detection of deoxyribonucleic acid replication in human metaphase chromosomes. Proc. nat. Acad. Sci. (Wash.), 70, 3395-3399.

Latt, S. A. (1974). Sister chromatid exchange indices of human chromosome damage and repair: detection by fluorescence and induction by mitomycin C. Proc. nat. Acad. Sci. (Wash.), 71, 3162-3166.

Lawler, S. D., Lobb, D. S., and Wiltshaw, E. (1974). Philadelphia-chromosome positive bone-marrow cells showing loss of the $\mathrm{Y}$ in males with chronic myeloid leukaemia. Brit. J. Haemat., 27, 247-252.

Lawler, S. D., O'Malley, F., and Lobb, D. S. (1976). Chromosome banding studies in Philadelphia chromosome positive myeloid leukaemia. Scand. J. Haemat., (In press).

Lawler, S. D., Secker Walker, L. M., Summersgill, B. M., Reeves, B. R., Lewis, J., Kay, H. E. M., and Hardisty, R. M. (1975). Chromosome banding studies in acute leukaemia at diagnosis. Scand. J. Haemat., 15, 312-320.

Leisti, J. T., Kaback, M. M., and Rimoin, D. L. (1975). Human X-autosome translocations: differential inactivation of the $X$ chromosome in a kindred with an X-9 translocation. Amer. J. Hum. Genet., 27, 441-453.

Lejeune, J., Lafourcade, J., Berger, R., Vialatte, J., Boeswillwald, M., Seringe, P., and Turpin, R. (1963). Trois cas de délétion partielle du bras court d'un chromosome 5. C.R. Acad. Sci. (Paris), 257, 3098-3102.

Lejeune, J., Turpin, R., and Gautier, M. (1959). Le mongolisme exemple d'aberration autosomique humaine. Ann. Génét., 1, 41-49.

Licznerski, G. and Lindsten, J. (1972). Trisomy 21 in man due to maternal non-disjunction during first meiotic division. Hereditas (Lund), 70, 153-154.

van der Linden, A. G. J. M., Pearson, P. L., and van der Kamp, J. J. P. (1975). Cytological assessment of meiotic exchange in a human male with a pericentric inversion of chromosome No. 4. Cytogent. Cell Genet., 14, 126-139.

Littlefield, L. G. and Goh, K.-O. (1973). Cytogenetic studies in control men and women. I. Variations in aberration frequencies in 29,709 metaphases from 305 cultures obtained over a 3-year period. Cytogenet. CellGenet., 12,1734.

Lobb, D. S., Reeves, B. R., and Lawler, S. D. (1972). Identification of isochromosome 17 in myeloid leukaemia. (Letter.) Lancet, 1, 849-850.

Luciani, J. M., Morazzani, M.-R., and Stahl, A. (1975) Identification of pachytene bivalents in human male meiosis using G-banding technique. Chromosoma, 52, 275282.

Lyon, M. F. (1961). Gene action in the X chromosome of the mouse (Mus musculus L.). Nature (Lond.), 190, 372-373.

McKenzie, W. H. and Lubs, H. A. (1973). An analysis of the technical variables in the production of $\mathrm{C}$ bands. Chromosoma, 41, 175-182.

McKenzie, W. H. and Lubs, H. A. (1975). Human Q and C chromosomal variations: distribution and incidence. Cytogenet. Cell Genet., 14, 97-115.

Manolov, G. and Manolova, Y. (1972). Marker band in one chromosome 14 from Burkitt lymphomas. Nature (Lond.), 237, 33-34.

Mark, J. (1975). Two pseudodiploid human breast carcinomas studied with G-band technique. Europ. J. Cancer, 11, 815819.

Mark, J., Mitelman, F., and Levan, G. (1972). On the specificity of the $\mathbf{G}$ abnormality in human meningiomas studied by the fluorescence technique. Acta path. microbiol. scand., 80A, 812-820.

Mastrangelo, R., Zuelzer, W. W., Ecklund, P. S., and Thompson, R. I. (1970). Chromosomes in the spinal fluid: evidence for mestastic origin of meningeal leukemia. Blood, 35, 227-235.

Matsui, S.-J. and Sasaki, M. (1973). Differential staining of nucleolus organisers in mammalian chromosomes. Nature (Lond.), 246, 148-150.

Miller, D. A., Allderdice, P. W., Miller, O. J., and Breg, W. R. (1971). Quinacrine fluorescence patterns of human Dgroup chromosomes. Nature (Lond.), 232, 24-27.

Mitelman, F., Mark, J., Nilsson, P. G., Dencker, H., Norryd, C., and Tranberg, K.-G. (1974). Chromosome banding pattern in human colonic polyps. Hereditas (Lund), 78, 63-68.

Mittwoch, U. (1967). Sex Chromosomes. Academic Press, New York and London.

Morad, M., Jonasson, J., and Lindsten, J. (1973). Distribution of mitomycin $\mathbf{C}$ induced breaks on human chromosomes. Hereditas (Lund), 74, 273-281.

Mukherjee, A. B., Blattner, P. Y., and Nitowsky, H. M. (1971). Sex-chromatin fluorescence in human amnioticfluid cells. (Letter.) Lancet, 2, 709-710.

Nowell, P. C. and Hungerford, D. A. (1960). A minute chromosome in human chronic granulocytic leukemia. Science, 132, 1497.

O'Riordan, M. L., Berry, E. W., and Tough, I. M. (1970). Chromosome studies on bone marrow from a male control population. Brit.J. Haemat., 19, 83-90.

Orye, E., Delbeke, M. J., and Vandenabeele, B. (1971). Retinoblastoma and D-chromosome deletions. (Letter.) Lancet, 2, 1376.

Oshimura, M. and Sandberg, A. A. (1975). Isochromosome 17 in prostatic cancer. J. Urol., 114, 249-250.

Oxford, J. M., Harnden, D. G., Parrington, J. M., and Delhanty, J. D. A. (1975). Specific chromosome aberrations in ataxia telangiectasia. J. med. Genet., 12, 251-262.

Page, B. M. (1973). Identification of chromosome 9 in human male meiosis. Cytogenet. Cell Genet., 12, 254-263.

Paris Conference, 1971 (1972). Standardization in human cytogenetics. Birth Defects, 8 (7).

Patau, K., Smith, D. W., Therman, E., Inhorn, S. L., and Wagner, H. P. (1960). Multiple congenital anomaly caused by an extra chromosome. Lancet, 1, 790-793.

Pearson, P. L. and Bobrow, M. (1970). Definitive evidence for the short arm of the $Y$ chromosome associating with the $\mathrm{X}$ chromosome during meiosis in the human male. Nature (Lond.), 226, 959-961.

Pearson, P. L., Bobrow, M., and Vosa, C. G. (1970). Technique for identifying $\mathrm{Y}$ chromosomes in human interphase nuclei. Nature (Lond.), 226, 78-80.

Perry, P. and Evans, H. J. (1975). Cytological detection of mutagen-carcinogen exposure by sister chromatid exchange. Nature (Lond.), 258, 121-125.

Perry, P. and Wolff, S. (1974). New Giemsa method for the differential staining of sister chromatids. Nature (Lond.), 251, 156-158.

Philip, P. (1975). Trisomy 8 in acute myeloid leukaemia. Scand. J. Haemat., 14, 140-147. 
Polani, P. E., Briggs, J. H., Ford, C. E., Clarke, C. M., and Berg, J. M. (1960). A mongol girl with 46 chromosomes. Lancet, 1, 721-724.

Prieto, F., Egozcue, J., Forteza, G., and Marco, F. (1970). Identification of the Philadelphia (Ph-1) chromosome. Blood, 35, 23-27.

Ratcliffe, S. G., Stewart, A. L., Melville, M. M., Jacobs, P. A., and Keay, A. J. (1970). Chromosome studies on 3500 newborn male infants. Lancet, 1, 121-122.

Reeves, B. R. (1973). Cytogenetics of malignant lymphomas. Studies utilising a giemsa-banding technique. Humangenetik, 20, 231-250.

Reeves, B. R., Lobb, D. S., and Lawler, S. D. (1972). Identity of the abnormal F-group chromosome associated with polycythaemia vera. Humangenetik, 14, 159-161.

Reeves, B. R. and Margoles, C. (1974). Preferential location of chlorambucil-induced breakage in the chromosomes of normal human lymphocytes. Mutation Res., 26, 205-208.

Reeves, B. R., Pickup, V. L., Lawler, S. D., Dinning, W. J., and Perkins, E. S. (1975). A chromosome study of patients with uveitis treated with Chlorambucil. Brit. med. J., 4, 2223.

Reeves, B. R. and Stathopoulos, G. (1976). Cytogenetic and cell-surface marker studies of two non-Hodgkin's lymphomata of T-cell origin. Hum. Genet., 31, 203-210.

Rowley, J. D. (1973). A new consistent chromosomal abnormality in chronic myelogenous leukaemia identified by quinacrine fluorescence and giemsa staining. Nature (Lond.), 243, 290-293.

Rowley, J. D. (1974). Nonrandom chromosomal abnormalities in hematologic disorders of man. Proc. nat. Acad. Sci. (Wash.), 72, 152-156.

Ruddle, F. H. (1973). Linkage analysis in man by somatic cell genetics. Nature (Lond.), 242, 165-169.

Schröder, J. (1975). Transplacental passage of blood cells. $J$. med. Genet., 12, 230-242.

Schroeder, T. M., Anschütz, F., and Knopp, A. (1964). Spontane Chromosomenaberrationen bei familiärer Panmyelopathie. Humangenetik, 1, 194-196.

Seabright. M. (1971). A rapid banding technique for human chromosomes. (Letter.) Lancet, 2, 971-972.

Seabright, M. (1973). High resolution studies on the pattern of induced exchanges in the human karyotype. Chromosoma, 40, 333-346.

Secker Walker, L. M. (1971). The chromosomes of bonemarrow cells of haematologically normal men and women. Brit. J. Haemat., 21, 455-461.

Shiraishi, Y., Hayata, I., Sakurai, M., and Sandberg, A. A. (1975). Chromosomes and causation of human cancer and leukemia XII. Banding analysis of abnormal chromosomes in polycythaemia vera. Cancer (Philad.), 36, 199-202.

Smith, D. W., Patau, K., Therman, E., and Inhorn, S. L. (1962). The No. 18 trisomy syndrome. J. Paediat., 60, 513527.
Solomon, E. and Bobrow, M. (1975). Sister chromatid exchanges-a sensitive assay of agents damaging humano chromosomes. Mutation Res., 30, 273-278.

Spiers, A. S. D. and Baikie, A. G. (1970). A special role of the $\overrightarrow{\overline{\vec{S}}}$ group 17,18 chromosomes in reticuloendothelial neo-? plasia. Brit. J. Cancer, 24, 77-91.

Steele, M. W. and Breg, W. R., Jr (1966). Chromosomeo analysis of human amniotic-fluid cells. Lancet, 1, 383-385. $\bar{\omega}$

Sumner, A. T. (1972). A simple technique for demonstrating centromeric heterochromatin. Exp. Cell Res., 75, 304-306.气

Sumner, A. T., Evans, H. J., and Buckland, R. A. (1971). New technique for distinguishing between human chromosomes. Nature New Biol., 232, 31-32.

Thomas, E. D., Buckner, C. D., Clift, R. A., Fass, L., Fefer, $\overrightarrow{ }$ A., Lerner, K. G., Neiman, P., Rowley, N., and Storb, R.w (1973). Marrow grafting in patients with acute leukemia? Transplant. Proc., 5, 917-922.

Tiepolo, L. and Zuffardi, O. (1973). Identification of normal and abnormal chromosomes in tumour cells. Cytogenet. Cell Genet., 12, 8-16.

Tjio, J. H. and Levan, A. (1956). The chromosome number ofir man. Hereditas (Lund), 42, 1-6.

Tjio, J. H., Puck, T. T., and Robinson, A. (1959). The somatico chromosomal constitution of some human subjects with genetic defects. Proc. nat. Acad. Sci. (Wash.), 45, 10081016.

Tough, I. M., Smith, P. G., Court Brown, W. M., and Harnden, D. G. (1970). Chromosome studies on workers exposed to atmospheric benzene. The possible influence of age. Europ. J. Cancer, 6, 49-55.

Turleau, C., Plachot, M., Chavin-Colin, F., Roubin, M.,ס Langmaid, H., Cochet, C., Blanc-Brude, M., Lety, M-A.O and de Grouchy, J. (1975). Distribution des points de cassure chromosomique dans les remaniements con $\overline{0}$ stitutionnels. Lyon méd., 233, 329-335.

Uchida, I. A. and Lin, C-C. (1971). Fluorescent staining of human chromosomes: identification of some common aberrations. Canad. med. Ass. J., 105, 479-482.

Wilson, M. G., Towner, J. W., and Fujimoto, A. (1973) Retinoblastoma and D-chromosome deletions. Amer. JJ hum. Genet., 25, 57-61.

Wurster-Hill, D. H., McIntyre, O. R., Cornwell, G. G., andMaurer, L. H. (1973). Marker chromosome 14 in multiplē myeloma and plasma-cell leukemia. (Letter.) Lancet, 2 ? 1031 .

Wyandt, H. E. and Hecht, F. (1971). Detection of the X? chromatin body in human fibroblasts by quinacring fluoromicroscopy. (Letter.) Lancet, 2, 1379-1380.

Zankl, H. and Zang, K. D. (1972). Cytological and cytogenetical studies on brain tumours. IV. Identification of the missing $\mathrm{G}$ chromosome in human meningiomas as No: 22 by fluorescence technique. Humangenetik, 14, 167-169.

Zech, L. (1969). Investigation of metaphase chromosomes with DNA-binding fluorochromes. Exp. Cell Res., 58,463 $\mathrm{O}$ 